\title{
Identifying Home Care Clinicians" Information Needs for Managing Fall Risks
}

Dari Alhuwail'; Güneş Koru'

${ }^{1}$ Department of Information Systems, University of Maryland, Baltimore County

\section{Keywords}

Home health agencies, health information technology, quality of care, workflow, information management

\section{Summary}

Objectives: To help manage the risk of falls in home care, this study aimed to (i) identify home care clinicians' information needs and how they manage missing or inaccurate data, (ii) identify problems that impact effectiveness and efficiency associated with retaining, exchanging, or processing information about fall risks in existing workflows and currently adopted health information technology (IT) solutions, and (iii) offer informatics-based recommendations to improve fall risk management interventions.

Methods: A case study was carried out in a single not-for-profit suburban Medicare-certified home health agency with three branches. Qualitative data were collected over a six month period through observations, semi-structured interviews, and focus groups. The Framework method was used for analysis. Maximum variation sampling was adopted to recruit a diverse sample of clinicians.

Results: Overall, the information needs for fall risk management were categorized into physiological, care delivery, educational, social, environmental, and administrative domains. Examples include a brief fall-related patient history, weight-bearing status, medications that affect balance, availability of caregivers at home, and the influence of patients' cultures on fall management interventions. The unavailability and inaccuracy of critical information related to fall risks can delay necessary therapeutic services aimed at reducing patients' risk for falling and thereby jeopardizing their safety. Currently adopted IT solutions did not adequately accommodate data related to fall risk management.

Conclusion: The results highlight the essential information for fall risk management in home care. Home care workflows and health IT solutions must effectively and efficiently retain, exchange, and process information necessary for fall risk management. Interoperability and integration of the various health IT solutions to make data sharing accessible to all clinicians is critical for fall risk management. Findings from this study can help home health agencies better understand their information needs to manage fall risks.

\section{Correspondence to:}

Güneş Koru

Department of Information Systems, University of Maryland, Baltimore County 1000 Hilltop Circle

Baltimore, MD 21250, USA

Email: gkoru@umbc.edu

\author{
Appl Clin Inform 2016; 7: 211-226 \\ http://dx.doi.org/10.4338/ACI-2015-11-RA-0160 \\ received: November 22, 2015 \\ accepted: January 26, 2016 \\ published: April 6, 2016 \\ Citation: Alhuwail D, Koru G. Identifying home care \\ clinicians' information needs for managing fall risks. \\ Appl Clin Inform 2016; 7: 211-226 \\ http://dx.doi.org/10.4338/ACI-2015-11-RA-0160
}




\section{Background}

Home healthcare, referred to as home care henceforth, is defined as episodic and intermittent secondary care services provided to home-bound patients in their homes. Serving mostly the elderly [1], home care involves skilled care services provided by nurses, physical therapists, occupational therapists, speech therapists, social workers, and home aides [2]. Home care is a critical component in the continuum of care for many patients who require recuperative and rehabilitative services after hospital discharges [3-6]. It enables patients to achieve better recovery, gain strength, regain functionality, and become independent more quickly [7].

Home care is an important component of the overall healthcare industry in the United States (US) with a projected increase in its utilization and expenditures. In 2013, approximately 3.5 million Medicare ${ }^{1}$ beneficiaries, who were 65 and above, received home care services from nearly 12,000 home health agencies (HHAs) [9]. This age group is projected to increase from 14 percent in 2010 to the levels of above 16 and 19 percents in 2020 and 2030, respectively [10], thus indicating a higher utilization of home care services [11]. In this context, providing quality home care is and will be essential in order to reduce expensive hospital re-admissions and emergency room (ER) visits [12, 13].

In home care, falls rank as the top potentially avoidable event that leads to hospital re-admissions and the ER visits $[14,15]$. For home care to fulfill its promises, effective management of fall risks is a necessity. Fall risk management is defined as determining a patient's fall risks in conjunction with the appropriate interventions to reduce those risks [16-18]. Therefore, identifying the clinicians' information needs to effectively manage fall risks in home care becomes an important goal, which is addressed by this study.

\section{Objectives}

To support fall risk management in home care, this study aimed to:

1. Identify home care clinicians' information needs for fall risk management and how they manage missing data or data of questionable validity or accuracy.

2. Identify the information management problems associated with retaining, exchanging, or processing information about fall risk management in the existing home care workflows along with the currently adopted health information technology (IT) solutions.

3. Offer a set of informatics-based recommendations to improve care coordination for fall risk management.

To our best knowledge, earlier research studies did not specifically address the set of objectives outlined above.

\section{Methods}

Study design and settings: The study was designed as a case study, where the case was a single HHA, because an inherent requirement was to uncover information needs as they occurred in the workplace. A case study design is appropriate when the observed phenomena are inseparable from their context [19]. The study was descriptive in nature and adopted qualitative research methods [20-22] to obtain rich and context-specific information. It took place at a suburban Medicare-certified HHA with three branches. This HHA is a part of a not-for-profit network including a rehabilitation center, physician practices, and two hospitals.

Participants: Maximum variation sampling [23] was used as a purposive sampling strategy to recruit the participants for each data collection step. This strategy helped ensure the heterogeneity of

\footnotetext{
1 In the US, the Medicare program, managed by the Centers for Medicare and Medicaid (CMS), is the federal health insurance program for people aged 65 years and above, as well as other younger people with certain disabilities or with end-stage renal disease [8].
} 
the participants for the purpose of obtaining different views, thus a comprehensive understanding of the research topic. The HHA was asked to identify a diverse group of full-time clinicians based on professional role, educational background, work location, and years of experience. The number of participants in the study was determined by the initial design, but the researchers made sure that data saturation occurred within the initially planned numbers. Participation was entirely voluntary and involved no incentives.

Measures and data collection procedures: Qualitative data were collected from home care clinicians over a six month period by conducting (a) observations, (b) semi-structured interviews, and (c) focus group discussions. Purposefully, data collection steps were executed sequentially. Starting with the observations allowed the researchers to gain deeper understandings of the phenomena early in the research. Later, the interviews helped uncover more details and clarify the findings. Finally, the focus groups helped further verify and validate the results by incorporating different perspectives. Prior to the start of data collection, the study was reviewed and approved by an Institutional Review Board (IRB) for ethical considerations and protection of human subjects.

(a) Observations: At this step, five clinicians were observed throughout their work days. The observations yielded a better understanding of the context and phenomena under investigation [24-26]. Similar observations were used in previous health IT studies [27-29]. The observations took place at patients' homes and during the commutes between the visits. Each observation lasted for approximately six to seven hours with an average of five visits per clinician lasting approximately one hour each. Field notes were gathered and kept in a hand-written journal with time stamps; discrete data elements with some free text were recorded. All field notes were typed at the end of each observation day.

As it relates to fall risk management, the researchers observed all care delivery activities, use of HHA's electronic health record $(\mathrm{EHR})^{2}$, and communications with other healthcare providers, such as fellow clinicians, the physician's office, or laboratory. As time allowed between visits, the researcher asked the clinician open-ended questions to clarify observations, such as about policies, procedures, or other influences on information needs and workflows for fall risk management.

(b) Semi-structured interviews: A semi-structured interview was conducted over the phone with each one of the twenty clinicians. Semi-structured interviews allowed the researchers to explore themes and topics as they emerged during the interview. Each interview involved one participant and lasted one hour on average. All interviews were audio recorded and transcribed by the researchers verbatim to ensure accuracy.

Using an interview guide developed earlier, the participants were asked to outline their workflows and describe the challenges associated with fall risk management in their workflows. Each participant was instructed to describe and discuss the availability of fall-related information and how he or she dealt with missing and inaccurate information.

(c) Focus groups: Four focus groups were conducted with fifteen clinicians. Only five clinicians who were involved in previous steps participated in the discussions. Focus groups helped the researchers finalize the results and validate the findings obtained from earlier steps.

A facilitator manual explaining how to run the focus groups was prepared ahead of time to ensure consistency across the focus groups [30]. Each focus group lasted approximately one and a half hours and involved four participants on average. The participants in each group were from different clinical backgrounds reflecting how the HHA organized its interdisciplinary care teams in the field. The participants were asked to review and comment on the list of identified information needs for fall risk management. The researchers then asked the participants to review and comment on a workflow map of a routine visit specific to their discipline, thus allowing them to reflect on their workflows, specific information needs, and challenges they encountered regularly when managing fall risks. The researchers audio-recorded and transcribed the discussions, took general notes, and collected the participants' handouts for analysis.

2 The researchers attended four EHR training sessions to gain insight how clinicians were trained to use it for managing fall risks. 
Data analysis: The Framework Method [31-33], a qualitative method used in many research domains, including healthcare [34-37], was used for data analysis. The observation field notes, the interview transcripts, as well as the focus group handouts, transcripts, and facilitator notes constituted the qualitative data to be analyzed. For this study, the researchers followed the steps outlined for Framework, which involved constructing an index, labeling data according to the index, and sorting, summarizing, and synthesizing the data. The analysis was iterative [38] and started immediately after the first observation. It continued throughout the study. To reach consensus, the researchers met regularly to discuss the findings from each step and resolved any inconsistencies in the analysis.

\section{Results}

Home care nurses, physical therapists, and occupational therapists, all of whom were full-time employees at the HHA, participated in the study throughout its various steps. The participants' profiles for each data collection step are illustrated in $>$ Table 1 . Data saturation was achieved on the sixteenth interview and after the third focus group; however, the researchers preferred a cautious approach and still completed all of the research activities as scheduled.

\subsection{Information Needs}

According to the results, the information needs can be categorized into six domains as illustrated in Table 2:

(i) Physiological: This domain encompasses information pertaining to disorders affecting organ and body system functions such as musculoskeletal disorders, cognitive impairments, or chronic conditions. It was vital to know the patient's current and accurate clinical and physical limitations for therapy to help mitigate falling risks (Q1 - Table 3 for selected representative quotes). The patient's ability to walk and move around the home was also important for fall risk evaluation; without which clinicians cannot predict the likelihood of a fall (Q2).

(ii) Care Delivery: This domain is associated with information that informs the HHA's fall risk management activities and workflows such as the hospital discharge information, rehab and therapy notes, and weight-bearing status. The clinicians wanted to know if their patients have received any rehabilitative care, its outcomes, and any fall precautions (Q3). Prior rehabilitation notes from any referring hospital, such as the patient's functional improvement as a result of therapy, were extremely helpful in evaluating the patient's fall risks (Q4). Additionally, the clinicians wanted an accurate account of all medications that can affect their patients' balance and increase the risk for falling (Q5 and Q6), such as those prescribed for blood pressure and cardiac problems.

(iii) Educational: This domain has information related to the educational needs of patients, caregivers, and clinicians for fall risk management. Examples include: patient education level and information on medications' effects on balance. The clinicians spent a considerable amount of time teaching their patients about medication effects on balance and fall risks (Q7). However, the clinicians had few resources, paper and electronic, readily available to them at patients' homes to provide effective and comprehensive teaching on fall risk management. It was also important to know whether patients and their caregivers have spoken or written language difficulties, which can detract from the quality of communication between themselves and the clinician, resulting in a failure to understand the instructions and increasing fall risks (Q8).

(iv) Social: This domain contains information regarding the patient's social ecosystem including culture, values, and caregiver availability. Due to the off-site nature of home care and the clinicians' inability to continuously monitor their patients for falls, it was important to know the caregiver availability for assistance with performing activities of daily living (ADLs) at home (Q9).

(v) Environmental: This domain is concerned with information that describes the physical environment in which the patient lives in. Examples include broken or uneven steps and surfaces or clutter in the home. The clinicians wanted information about the patient's home environment, whether it was cluttered or not, and how it affected the patient's ambulatory efforts (Q10).

(vi) Administrative: This domain has information that is usually non-clinical in nature, yet crucial for fall risk management activities and day-to-day operations. Examples include patient phone 
and address, insurance information, and appointment scheduling. During the observations, all the clinicians verified patient phone numbers, insurance information, and upcoming appointments prior to leaving the home.

\subsection{Dealing with Missing, Incomplete, or Inconsistent Data}

The clinicians stressed that they started the care episode with little information important to fall risk management efforts (Q11). It was observed that the clinicians mainly received information from hospital discharge summary sheets, which included diagnosis, brief medical history, reason for referral to home care, hospital prescribed medications, and patient allergies; all without specific relevance to fall risk management. Many of the educational, social and environmental information critical for fall risk management were not exchanged. For example, the rehab notes, durable medical equipment (DME) orders, and patient psychosocial state were rarely communicated to the HHA.

At times, home care medical orders were general or imprecise without specific information that informs fall risk management interventions (Q12). For example, one medical order received by the HHA read "provide PT [physical therapy] as needed" without specifying goals for fall risk management. Worse, the information in the HHA's EHR and printed hospital discharge record were different or inconsistent: many times the clinicians treated their patients for reasons other than the diagnosis reported in the hospital's discharge record (Q13 and Q14). The examples of frequently inconsistent data include weight-bearing status and balance problems. Dealing with missing or inaccurate data for fall risk management was taxing. Ensuring that patient information is error free was not straight forward and required dedicating extra time and resources (Q15 and Q16). For example, asking the patient about the names of recently changed medications after visiting their primary care physician. It was more difficult if patients and their caregivers could not ascertain the correct information due to dementia (Q17 and Q18). Therefore, clinicians communicated with their colleagues, physicians, or laboratory facilities to seek more accurate and current information that informs fall risk management (Q19 and Q20). Yet, there seemed to be lack of care coordination between multiple physicians caring for the same patient (Q21), which hindered fall risk management efforts at the HHA.

Despite such difficulties, patients and their caregivers expected that clinicians were able to resolve inconsistencies and inaccuracies in the data, otherwise the patient-clinician trust would be lost (Q22). When evaluating fall risk management efforts at the HHA, clinical supervisors also dealt with missing or inaccurate data. One clinical supervisor complained of how complex and time wasting fact finding can be when conducting quality investigations after a patient falls (Q23). Such information was critical for refining falls-specific interventions and quality improvement efforts at the HHA.

\subsection{Information Management Problems}

The results showed that the workflows were complex and involved many problems with eliciting, exchanging, and processing information relevant to falls (Q24). The HHA received little information from the referring hospitals at the start of care relevant to fall risk management. Most referrals were sent via fax and were sometimes illegible. Very few referrals were entered directly into the EHR by the HHA's liaison at the hospital. Most of the information provided in the referral were clinical in nature; many of the non-clinical information critical for fall risk management were not exchanged. For example, information regarding the patient's wight-bearing status (care delivery), language and interpretation needs (social), or caregiver availability (social), were not included in the referrals.

When the intake department received the referral via fax, clinical information was primarily entered into the EHR without specific relevance to fall risk management. While the intake staff are trained clinicians, they selectively entered what they deemed relevant for the overall home care episode without close attention to fall risks. Home care appointments were scheduled based on the referral information and patients' clinical needs. Most clinicians reviewed the patient file on the EHR a day before the scheduled visit and some called their patients to make sure that the address was correct and that they will be home. At this step, clinicians usually did not ask their patients specific questions related to fall risks. 
At patients' homes, the clinicians sometimes had a need to communicate with other clinicians or healthcare providers to request, obtain, or verify information that were necessary for fall risk management. For example, during an observation, one patient using crutches to move around his home was not provided with scheduled physical therapy services because his weight-bearing status could not be verified. The physical therapist asked the patient and caregiver about his recent appointment to the orthopedic specialist and if the weight-bearing status changed, but neither could remember; the EHR had no related notes either. The therapist tried calling the physician's office, however no one was available to provide her with an answer; and, she was told that she would receive the information verbally over the phone. However, the therapist did not receive the information during the visit, thus the patient was arguably at a higher risk for falling because he could not receive the therapeutic services that would enable him to move safely at home. While the EHR was capable of exchanging secure messages between the HHA clinicians, it did so asynchronously, not in real-time. Clinicians had to synchronize their data with the main servers using a secure network to receive updates or send messages.

\subsection{Current Health IT Solutions}

The clinicians mainly used the two available health IT solutions for fall risk management: the EHR and an online application to report fall incidents. The clinicians were able to access these solutions remotely using laptops. The EHR used by the HHA had tabs and checklists for fall risk management. For example, the clinicians were able to use the Missouri Alliance for Home Care (MAHC)[39] fall risk assessment tool to calculate their patients' fall risks. However, the clinicians mostly used it once, at the initial admission to home care, hence the results from the assessment did not change. The assessments were also not saved to a common place where all clinicians can view them readily. In fact, the only way to access the assessment is navigating through the many clinical notes one-by-one and searching for it. Finding and reviewing falls-specific information in the EHR was not straightforward and often times required complex navigation within the system (Q25 and Q26).

Despite the online availability of the EHR from patients' homes, clinicians reported that documentation during the visit was ineffective and inefficient for fall risk management. They emphasized that home care services often required clinicians to work within close proximity of their patients or even hold them sometimes, especially those that were at a higher risk for falling, thus indicating the clinicians' inability to document and provide care at the same time (Q27 and Q28). Because the clinicians travelled between homes and saw many patients during the day, it was difficult to keep up with the documentation of information for fall risk indicators and interventions (Q29 and Q30). It was observed that the clinicians took brief clinical notes, including information related fall risk management, either on paper or in the EHR, and completed the EHR documentation at the end of the day (Q31). However, fall-risk assessments were completed directly in the EHR at the patient's home using the laptop. Another issue was that the documentation itself was focused on procedural notations rather than providing useful insights that inform fall risk management (Q32). The EHR allowed clinicians to record the number of exercises, the devices used for moving around the home, and vital signs. However, it did not show the patient's progress and adherence to fall-risk interventions and advice.

The HHA also used a separate online reporting application to enter witnessed and unwitnessed patient fall incidents; the application was available via the internet and accessible on the clinicians' laptops in their patients' homes. This application allowed for comprehensive and fall-specific data collection such as the location of the fall, any interventions that were taken beforehand, and contributing factors that may have affected the outcome of the fall. It was observed that some clinicians documented fall incidents during the visit by asking the patients or their caregivers directly if they were available. Other clinicians took some notes on the incident on a piece of paper and entered the information at the end of the day after reviewing their handwritten notes. After clinicians reported a fall, their reports got reviewed by supervisors and quality assurance staff members. The clinicians were notified only after the reviews were completed, which usually took several weeks, and only for severe cases where harm from the incident resulted in an emergency room visit or hospital readmissions. 
Although the HHA adopted some health IT solutions to help with fall risk management, it was evident that there were substantial limitations associated with responding to the clinicians' relevant information needs in their workflows.

\section{Discussion}

Our results show that home care clinicians today often start caring for their patients with little important information that informs the care plan and critical to fall risk management; earlier studies have reported similar results $[40,41]$. Several clinicians in our study reported challenges with the availability and accuracy of fall-risk related information, such as the weight-bearing status and DME orders from the start. The unavailability and inaccuracy of such critical information in the EHR can delay necessary therapeutic services aimed at reducing the patients' fall risks and thereby jeopardizing their safety.

In addition, the clinicians did not have access to an updated and current medications lists in the EHR; the information from the referring hospitals were partial, incomplete, or inaccurate. Having a current and reconciled list of medications, highlighting those that can affect the patient's balance and his or her ability to move, is critical to fall risk management efforts in home care [42]. It is important that all clinicians caring for the patient, have access to the same medications list, regardless of the format, paper or electronic [43,44], otherwise, clinicians will not be able to make informed care decisions to manage fall risks.

In this study's context, the lack of effective and coordinated home care services critical for fall risk management is indicated by gaps in the workflows and exchanged information. These gaps are created as a direct result of the inability to capture and exchange fall-related information electronically in the EHR or via Health Information Exchanges (HIEs) [45]. Without explicit attention to fall-related information, such gaps can also be influenced by clinicians' understanding of the scope and content of the information to be exchanged according to their discipline, context, and healthcare organization they work in [46].

Importance of contextual data: Important contextual information such as those in the educational, social, and environmental domains ( $>$ Table 2) are critical to fall risk management, care workflows, and safer care practices in home care. Unfortunately, our results demonstrate that such information is not exchanged or even captured easily in either written or electronic format; it is often not documented and remains in the memory of clinicians [47].

If clinicians provide culturally congruent care to deliver more culturally sensitive fall-related clinical advice, it will be well received by patients and their caregivers [48, 49]. The clinicians should create a partnership with the patients and their caregivers to jointly develop a care plan that meets patients' and caregivers' sociocultural and healthcare needs. Doing so will ensure that patients and caregivers understand how fall risk management interventions fit within their cultural practices [50]. It is likely that once patients and caregivers feel that their culture, customs, and religion were understood by clinicians, they will be more receptive to fall-specific interventions and clinical advice.

While contextual data is critical and relevant to managing falls, caution must be taken not to use such data to discriminate against patients and their caregivers [51]. Rather, such information should be used to provide more culturally- and socially-sensitive care. It is also important to note that knowing such information may not be enough; clinicians must receive training on a continual-basis to become more sensitive, understanding, and aware of such factors.

Currently adopted health IT solutions: While health IT solutions play a critical role in the rapid and systematic collection and transfer of information critical to fall risk management [52-55], their benefits and full potential were not realized in the HHA studied. We observed that fall-related data were reported from multiple sources, however, there were many missing, incomplete, or inconsistent data in the currently adopted health IT solutions at the HHA. 
Despite the EHR's capability to exchange Continuity of Care Documents (CCDs) ${ }^{3}$, the HHA did not utilize such function nor did it partake in any HIE networks. Presently, the CCD has no specific placeholder for patient culture, language barriers, or home environment hazards relevant to fall risks. While this standard may not be the answer, it is a step in the right direction.

Slow connections and network coverage issues throughout the areas serviced by the HHA limited the number of times clinicians synchronize the EHR to receive updates or send messages. Moreover, even after synchronization, clinicians did not get notified of incoming messages from their colleagues. They had to navigate to the specific patient record and view the messages tab.

Hence, they often left voicemails for their colleagues to check the messages queue in the EHR. These tedious steps eat away from the clinician's limited time and productivity. Consequently, the patient's fall risk increases when an important message is overlooked or missed.

Additionally, while it is beneficial to utilize a specialized application to report and capture comprehensive information related to falls, the application used by the HHA does not help detect any patterns or offer warnings to clinicians about their patients' fall risks. In addition, the application is not integrated with the EHR and the data does not transfer to the patient's electronic medical record.

\section{Informatics-Based Recommendations}

To improve communication and coordination critical for fall risk management, the HHA should consider interoperability and integration of its various health IT solutions and make data sharing accessible to all clinicians. The EHR should utilize the CCD's ability of exchanging specific data elements that can help inform fall risk management interventions such as clinical problems, functional status, life style, and ethnicity.

Since the clinicians had access to the EHR on their laptops, it would be useful for the to upgrade its EHR's messaging capability to become synchronous and prompt. The EHR should be capable of notifying the clinicians immediately if they received a message from other members of the home care team without going through numerous screens to read a message or review an alert. Doing so can reduce the time and effort spent by clinicians when calling other team members to report a recently prescribed medication that affects the patient's balance for example. In the long run, the HHA should also consider redesigning its EHR to better support its workflows. A well designed system may reduce the need for instant messaging needs. Receiving multiple instant messages in their busy day may overwhelm the clinicians with information. In fact, a recent study reported that electronic communication worsened the healthcare providers' agreement regarding the plan of care [58].

Raising awareness on the importance of the information related to fall risk management through educational seminars and training is essential for all HHA clinicians and staff members. Such training can allow clinicians to understand each other's roles and what information each discipline requires to better manage the risk of falls. This awareness training needs to be extended to all referring organizations outside the HHA as well, including the hospitals, physician offices, and other healthcare providers.

Furthermore, the EHR training provided to the HHA clinicians must go beyond the procedural steps of using the system for documentation purposes into what information is important for fall risk management, how to document it, and where to locate it. Ultimately however, the HHA must also consider evaluating the usability and ease-of-use of its EHR and other health IT solutions on a regular basis to facilitate their usefulness and effectiveness.

Vendors of health IT solutions, including EHRs and HIEs, must develop solutions that are responsive to the diversity of home care clinicians' information needs for fall risk management. Health IT solutions must enable clinicians to capture fall-related information at the point-of-care effectively and smoothly; these solutions must also store the information critical for fall risk management in a

3 An XML-based markup standard for exchanging patient summaries [56, 57].

C) Schattauer $2016 \quad$ D. Alhuwail, G. Koru. Identifying home care clinicians' information needs for managing 
logical and easy to find manner. Such solutions must also offer intelligent and proactive clinical decision support functions to manage fall risks, based on historical and trend data in the patient's record.

\section{Limitations}

Similar to other research, this study is not free of limitations. The case study limited the focus on one HHA, however, we collected data across its three branches and ensured the diversity of participating clinicians based on professional role, educational level, and experience. Physicians, home health aides, and social workers hired as part-timers were not included in the study because no compensation could be offered for their time. However, full-time clinicians, i.e., the nurses, physical therapists, and occupational therapists providing a great majority of services, were included and they provided rich information. Another limitation stems from the qualitative nature of our study and the methods used. Due to limited evidence on this topic, the study was purposefully designed to obtain rich and contextual information, not to obtain immediately generalizable results. Caution should be used before directly assuming generality of results by ignoring the specific context of an HHA. Future studies adopting quantitative research methodologies, e.g. surveys, can provide evidence collected from a large number of home care clinicians working at multiple HHAs across geographic boundaries to draw further generality.

\section{Conclusions}

Overall, the information needs relevant for fall risk management in home care were categorized into six domains namely physiological, care delivery, educational, social, environmental, and administrative. Based on their clinical discipline, the clinicians had various information needs, however, there was a general agreement among them on the importance of having a brief fall-related patient history. The unavailability and inaccuracy of critical information related to fall risks can delay necessary therapeutic services aimed at reducing the patient's fall risks and thereby jeopardizing their safety. The currently adopted IT solutions did not adequately accommodate fall-related data and the electronic communication between clinicians was fragmented. Home care workflows and health IT solutions must effectively and efficiently retain, exchange, and process information necessary for fall risk management. Educational seminars and training on the importance of the information related to fall risk management is essential for all HHA clinicians, staff members, and outside healthcare providers. Looking forward, given an increasingly aging population in the US, the findings from this study can help HHAs better understand their information needs to manage fall risks.

\section{Clinical Relevance}

The evidence from this research identified essential information needs of home care clinicians for fall risk management. HHAs can use this evidence to improve and optimize their workflows and currently adopted health IT solutions to ensure that their clinicians' fall risk information needs are met. Consequently, improved care coordination can lead to improved quality of care and health outcomes benefiting patients and their families.

\section{Conflicts of Interest}

The authors declare that they have no conflicts of interest in the research.

\section{Protection of Human Subjects}

The study was performed in compliance with the World Medical Association Declaration of Helsinki on Ethical Principles for Medical Research Involving Human Subjects, and was reviewed by University of Maryland, Baltimore County Institutional Review Board.

\section{Acknowledgements}

We would like to acknowledge the tremendous help and support from the Maryland Health Care Commission (MHCC) and the Maryland-National Capital Homecare Association (MNCHA). 
Table 1 Demographics of study participants.

\begin{tabular}{|c|c|c|c|}
\hline & $\begin{array}{l}\text { Observations } \\
(n=5)^{*}\end{array}$ & $\begin{array}{l}\text { Interviews } \\
(n=20)^{*}\end{array}$ & $\begin{array}{l}\text { Focus Groups } \\
(n=15)^{*}\end{array}$ \\
\hline \multicolumn{4}{|l|}{ Professional Role } \\
\hline Nurse & 2 & 9 & 5 \\
\hline Physical Therapist & 2 & 8 & 6 \\
\hline Occupational Therapist & 1 & 3 & 4 \\
\hline \multicolumn{4}{|l|}{ Educational Level } \\
\hline Diploma & 1 & 1 & 0 \\
\hline Bachelors & 2 & 11 & 13 \\
\hline Graduate & 2 & 8 & 2 \\
\hline \multicolumn{4}{|l|}{ Age } \\
\hline 30-40 years & 2 & 3 & 6 \\
\hline $41-50$ years & 2 & 5 & 4 \\
\hline $51>$ years & 1 & 12 & 5 \\
\hline \multicolumn{4}{|l|}{ Experience } \\
\hline $1-10$ years & 2 & 4 & 4 \\
\hline $11-20$ years & 2 & 5 & 6 \\
\hline $21>$ years & 1 & 11 & 5 \\
\hline \multicolumn{4}{|l|}{ Work Location } \\
\hline Branch 1 & 3 & 10 & 7 \\
\hline Branch 2 & 2 & 7 & 6 \\
\hline Branch 3 & 0 & 3 & 2 \\
\hline
\end{tabular}

* The numbers report the total of participants in each part of the study. Some participants were involved in more than one part of this study.

Table 2 Home care providers' information needs for managing and reducing the risk of falls.

\begin{tabular}{|l|l|}
\hline Domain & Information Needs \\
\hline Physiological & - Previous history of falls \\
& - Functional status \\
- Difficulties with walking and balance \\
- Musculoskeletal disorders (e.g. Osteoporosis) \\
- Vestibular disorders \\
- Vision problems \\
- Cognitive impairments \\
- Neurological problems (e.g. Parkinson's disease) \\
- Acute conditions (e.g. Orthostatic hypotension) \\
- Chronic conditions (e.g. Diabetes) \\
- Nutritional problems
\end{tabular}


Table 2 Continued

\begin{tabular}{|c|c|}
\hline Domain & Information Needs \\
\hline Care Delivery & $\begin{array}{l}\text { - Brief medical history (i.e. summary of recent encounters) } \\
\text { - Hospital discharge information, including: } \\
\text { - Reason for hospital admission } \\
\text { - Major events during hospital stay } \\
\text { - Medications affecting balance (e.g. drugs for hypertension) } \\
\text { - Rehab and therapy notes (i.e. therapy prognosis) } \\
\text { - Durable Medical Equipment (DME) prescribed and order status } \\
\text { - Concise home care orders, including: } \\
\text { - Specific fall risk management goals } \\
\text { - Expected outcomes of fall risk reduction interventions } \\
\text { - Weight-bearing status (if indicated) } \\
\text { - Assessments (e.g. Functional Gait Assessment) } \\
\text { - HHA fall risk management procedures }\end{array}$ \\
\hline Educational & $\begin{array}{l}\text { - Patient education level } \\
\text { - Patient comprehension } \\
\text { - Information on medications' effects on balance } \\
\text { - Information on condition/disease's effects on balance } \\
\text { - Treatment options and their fall risks }\end{array}$ \\
\hline Social & $\begin{array}{l}\text { - Patient psychosocial state } \\
\text { - Patient culture, customs, and religion } \\
\text { - Patient values and preferences specific to fall interventions } \\
\text { - Socioeconomic status } \\
\text { - Language and interpretation needs } \\
\text { - Caregiver availability }\end{array}$ \\
\hline Environmental & $\begin{array}{l}\text { - Broken/uneven steps and surfaces } \\
\text { - Throwrugs and clutter } \\
\text { - Absence of handrails }\end{array}$ \\
\hline Administrative & $\begin{array}{l}\text { - Patient demographics } \\
\text { - Patient phone and address } \\
\text { - Next of kin and caregiver contact information } \\
\text { - Insurance and coverage information } \\
\text { - Scheduling and appointment changes }\end{array}$ \\
\hline
\end{tabular}

Table 3 Selected representative quotes from the interviews and focus groups.

Q1. The biggest complaint I get from the therapists is weight bearing status being inaccurate and that's a big problem. (I-8)

Q2. How far they can walk, are they using a walker, or using a cane, can they, have they gone up and down stairs and all of that? (I-5)

Q3. Were they hospitalized? Did they go to rehab? What was their hospital diagnosis? What's their discharge from rehab diagnosis? Are they on any precautions, isolation precautions? Do they have any lines in them? Do they have any drains in them? Wounds? Are they mobile? What are their allergies? What is their diet? (I-2) Q4. Did they go to rehab? If they did, I would read some of the therapy notes from the rehab. That is really helpful to know. (I-3).

Q5. Sometimes medications can put patients at risk for falls and once again, just being able to monitor the medications that physicians are prescribing these patients. (I-6)

Q6. If someone's having a specific symptom, whether it's dizziness or fatigue or whatever, sometimes I have gone in and looked at all the medication and just then looked at all the side effects and see if there's anything in particular pop up that might be contributing to that, that might be contributing to their losing their balance or falling. (I-11) 


\section{Table 3 Continued}

Q7. Educating a lot about the medications they're taking and symptoms they might be having based on what condition they have and how that might be affecting their balance. (I-11)

Q8. I always ask them to have a family member around that is fluent in English. (I-10)

Q9. Who they live with and availability of caregivers? ... and willingness of those caregivers. (I-4)

Q10. We might look like exterior but we're more focused on the interior. The clutter, the walking pathways, the ability to get into the bathroom, access to the toilet, to shower, just that kind of, anything that will trip you up during your ADL's are sort of the focus of the OT I would think. (FG1-P1)

Q11. There are a lot of information that referral sources doesn't give us, we just have to do our own investigation. (I-1)

Q12. The orders are often just so vague. (I-11)

Q13. What is an issue is been able to get the same information, that's available for a patient when they are in the hospital. (I-2)

Q14. Little things like, patient actually has a UTI but it only says confusion. Well, why do they have confusion? Because they had a UTI. But now the patient's fine, but it doesn't say they had a UTI in there. So stuff like that happens. (FG2-P1)

Q15. It's a lot of extra steps. A lot of extra figuring it out. (I-3)

Q16. I have had some that had taken four hours because you get in the house and the medication are a disaster. No one knows anything. (I-10)

Q17. The problem is when there is an error and the person right in front of you cannot give you what's accurate. (I-15)

Q18. You can't take the person's [patient] word for it because sometimes It's not on the discharge summary and then you're just sitting and waiting and then you're either putting them at an increase at risk while they could have been weight bearing in tolerated or it's unsettling, you're leaving there without any kind of order. Sometimes you'll get the wrong information from intake, which is probably like getting it from discharge summary which is wrong, or you get no information and you are literally looking at a discharge summary of a broken hip that doesn't have any weight bearing. (FG1-P3)

Q19. If a patient has got dementia and they've got a family member around, it can really help you out. You've got to go to the primary care doctor because a lot of times they know the patient or they can give you some information and that's where you've got to go when the patient can't give it to you. And sometimes they don't even have it because they haven't seen the patient in a while so we do scratch our heads a lot and just try to do the best we can with what we're seeing, what we're assessing at that moment. (I-10)

Q20. I call the doctor and try to talk to them. I have another therapist that's joining to be taking over for me because there was a different area than mine and talking to her about it. (I-3)

Q21. Many patients, have multiple physicians. And there's no coordination between those physicians as well, which makes it extremely difficult because you talk to one, and then he wants to know what's going on and then he says, 'Well I don't know anything about this so I don't want to deal with this problem' even though he may have prescribed the medication which you're calling about. (I-9)

Q22. You need them to know that they can trust you and help problem solve and things like that when things aren't clear and accurate. (I-3)

Q23. I have five screens up when I'm going through that stuff. There are so many different what ifs, and so many different checks and balances. Where one screen can actually be reflecting something that's not accurate so I have to go in and see what the other screen shows. So, that's ridiculous. (I-8)

Q24. Starts of care are very extensive, very extensive amount of paperwork, takes two hours in the home by checking their I.D.'s, checking all their insurance, checking seeing all their medication, bring all of their medication with them, entering them into the computer, all of that into the computer. And then doing what they call the OASIS start of care, which is Medicare-mandated specific questions that have to be answered and filled out. Walking the patient, taking them to the bathroom, having them get up and down, off the toilet, checking their safety at the same time I'm walking them, and when documenting all that, takes approximately at minimum an hour depending on how extensive that start of care was. What their diagnosis was and what it took to do it. And then at the end of the day, I'm retransferring, of course, sometimes usually during the day to send things off if need be. If things need to be done and ordering supplies, I order all the supplies from the patient's home by sending case communication notes to a specific person and the agency who pulls those off of the computer and then orders the supplies. And that all has to be done before two o'clock so that it can be sent the next day's delivery by FedEx. Then when I get home I transfer immediately to see if there's changes for the next day and then it starts again. (I-9) 


\section{Table 3 Continued}

Q25. [EHR] doesn't log the visits in one log, you have to keep going back to individual visits. So if you're searching for something in somebody else's notes. Like if you're looking for something in the nurses notes like if they have addressed this or seen it or note. You have to click into every single note and click out of it and into that individual screen, you have to figure out or guess where that person may have put that information. You may think I put everything in the clinical note, I'll go to the clinical note. But that person may put it in the objective text, then you're just searching and guessing. There doesn't seem to be one clear uniformed way. I started five months ago and there wasn't really any guideline given to me of where I put it or how specific orientation is very focused on procedures, and company procedures and it's not specific to your discipline and where you should be addressing your notes and where things should go and you learn along the way. One thing that drives me crazy is that we do balance tests with people because were trying to reassess their fall risk and it's in your clinical note and you're trying to figure out, I'm doing the same balance test today, trying to find where you did your score before and can't find it. (FG1-P2)

Q26. Looking in the right place is a big problem with this documentation format that we have, yes. If it was all on one screen. It's the most tedious system I have ever seen. (FG1-P1)

Q27. As an OT I might be helping a person with a shower, or dressing, I might be in the kitchen with someone. And I can't really disengage form the therapeutic process to disengage and write in my note while I'm sitting there, it's really rude. It doesn't go over well. (FG1-P3)

Q28. The patients that are most involved, that need to have more description in the clinical notes, those are the patients that you are hands on the entire session. Those patients that need more physical assist, those are the ones that you need to do the most explaining on, those are the ones that are probably going back to the hospital, those are the ones that are probably going to fall and those are the ones that you probably don't get the chance that much in the setting to document all the things. (FG1-P2)

Q29. You have to remember things and so when you see people and you've jotted a few notes and you're running from house to house. You may finish your documentation and then that night when you're going to sleep you'll be like I forgot this. (FG1-P2)

Q30. You are subject to having to remember so of the different things you don't have someone documenting right there in the home. (I-7)

Q31. The only reason I consider it a problem is you're just putting in your basic clinical notes a lot of the time ... You'll say to yourself I know I did some med teaching, I'll put the name of the med, but I don't go into detail until I get home about what I actually taught them. Just enough to trigger my memory. If I sat there and did this whole thing, this so-called 30 minute skilled nurse visit it always turns into an hour. Basically that's how long it takes for a nurse to be as thorough as we're expected to be we're looking at an hour and fifteen minutes. For us to do that many patients, 5-6 patients, and then with travel time, you're spent. And then you still have to fine tune it when you get home. (FG2-P2)

Q32. Sometimes with our documentation we get really geared into these are the exercises that we did, these are the number of exercises that we did. This is the device that we walked with, this is how far we walked, and these are our vital signs. That doesn't tell you a whole lot, it tells you what you did. But it's really not telling the story of the patient, like are they being compliant with the use of their assisted device, is there all the clutter. Can they get their walker into the bathroom, because the doorway is too narrow. (FG1-P2)

Abbreviations - Q: Quote, I: Interview, FG: Focus Group, P: Participant, RN: Registered Nurse, OT: Occupational Therapist, ADLs: Activities of Daily Living, UTI: Urinary Tract Infection, ICU: Intensive Care Unit, EHR: Electronic Health Record, OASIS: Outcome and Assessment Information Set 


\section{References}

1. Centers for Medicare and Medicaid Services. Medicare \& Medicaid statistical supplement. Office of Information Products and Data Analysis; 2013.

2. Centers for Medicare and Medicaid Services. Home health care: What it is and what to expect [Internet]; 2014 [cited 2015-11-1]. Available from: http://www.medicare.gov/ what-medicare-covers/home-healthcare/.

3. Evashwick C. Creating the continuum of care. Health matrix 1989; 7(1): 30-39.

4. Fishman EZ, Penrod JD, Vladeck BC. Medicare home health utilization in context. Health services research 2003; 38(1p1): 107-112.

5. McNabney MK, Willging PR, Fried LP, Durso SC. The „continuum of care“ for older adults: Design and evaluation of an educational series. Journal of the American Geriatrics Society 2009; 57(6): 1088-1095.

6. Jarousse LA. The future of care. Part II: The continuum of care. Hosp Health Netw 2010 May; 84(5).

7. Hughes SL, Ulasevich A, Weaver FM, Henderson W, Manheim L, Kubal JD, Bonarigo, F. Impact of home care on hospital days: A meta analysis. Health Serv Res 1997; 32(4): 415-432.

8. Centers for Medicare and Medicaid Services. What's Medicare? 2015 [cited 2015-12-31]. Available from: https://www.medicare.gov/sign-up-change-plans/ decide-how-to-get-medicare/whats-medicare/what-ismedicare.html.

9. Centers for Medicare and Medicaid Services. CMS announces payment changes for Medicare home health agencies for 2015; 2014 [cited 2015-12-31]. Available from: https://www.cms.gov/newsroom/mediare leasedatabase/fact-sheets/ 2014-fact-sheets-items/2014-10-30.html.

10.Bureau UC. An Aging Nation: The Older Population in the United States; 2015. Available from: http://www.census.gov/library/publications/2014/demo/p25-1140.html.

11.Centers for Medicare and Medicaid Services. National health expenditure projections; 2012 [cited 2015-12-31]. Available from: https://www.cms.gov/ Research-Statistics-Data-and-Systems/StatisticsTrends-and-Reports/ NationalHealthExpendData/.

12.Lichtenberg FR. Is home health care a substitute for hospital care? Home Health Care Serv Q 2012; 31(1): 84-109.

13. Pigott HE, Trott L. Translating research into practice: The implementation of an in-home crisis intervention triage and treatment service in the private sector. Am J Med Qual 1993; 8(3): 138-144.

14. Centers for Medicare and Medicaid Services. Potentially avoidable event measures (PAE): OASIS-C based Home Health Agency Patient Outcome, Process and Potentially Avoidable Event Reports; 2015 [cited 2015-12-31]. Available from: https://www.cms. gov/Medicare/Quality-Initiatives-Patient-Assessment-Instruments/OASIS/ 09aa_hhareports.html.

15. Courtney MD, Edwards HE, Chang AM, Parker AW, Finlayson K, Hamilton K. A randomised controlled trial to prevent hospital readmissions and loss of functional ability in high risk older adults: a study protocol. BMC Health Services Research 2011; 11: 202.

16. Taylor JA, Parmelee P, Brown H, Ouslander J. The falls management program: A quality improvement initiative for nursing facilities $2005 ; 290-00-0011$.

17. Stevens JA, Noonan RK, Rubenstein LZ. Older adult fall prevention: Perceptions, beliefs, and behaviors. American Journal of Lifestyle Medicine 2010; 4(1): 16-20.

18. Stevens J. A CDC compendium of effective fall interventions: What works for community-dwelling older adults. 3rd ed. Atlanta, GA: Centers for Disease Control and Prevention. National Center for Injury Prevention and Control. Division of Unintentional Injury Prevention; 2015.

19. Yin RK. Case study research: Design and methods. Los Angeles, CA: SAGE Publications; 2014.

20. Ritchie J, Spencer L. Qualitative data analysis for applied policy research. In: Bryman A, Burgess RG, editors. Analysing qualitative data. Routledge; 1994. p. 173-194.

21. Kitzinger J. Qualitative research: Introducing focus groups. British Medical Journal 1995; 311(7000): 299-302.

22. Parsons M, Greenwood J. A guide to the use of focus groups in health care research: Part 1.m Contemporary nurse 2000; 9(2): 169-180.

23. Creswell J. Data collection. In: Creswell J, editor. Qualitative inquiry and research design: Choosing among five approaches. 2nd ed. Thousand Oaks, CA: SAGE Publications; 2007. p. 125-129.

24. Jorgensen DL. Participant observation: a methodology for human studies. Thousand Oaks, CA: SAGE Publications; 1989.

25. Kawulich BB. Participant observation as a data collection method. Forum: Qualitative Social Research. $2005 ; 6(2)$.

26.DeWalt KM, DeWalt BR. Participant observation: A guide for fieldworkers. 2nd ed. Walnut Creek, CA: Rowman Altamira; 2010. 
27. Unertl KM, Weinger M, Johnson K. Variation in use of informatics tools among providers in a diabetes clinic. AMIA Annual Symposium Proceedings. 2007; 756-760.

28. Unertl KM, Weinger MB, Johnson KB, Lrenzi NM. Describing and modeling workflow and information flow in chronic disease care. Journal of the American Medical Informatics Association 2009; 16(6): 826-836.

29. Flanagan ME, Saleem JJ, Millitello LG, Russ AL, Doebbeling BN. Paper- and computer-based workarounds to electronic health record use at three benchmark institutions. Journal of the American Medical Informatics Association 2013; 20(e1): e59-e66.

30.Dawson S, Manderson L, Tallo VL, Mutharayappa R, Farkas J, Hogan D, Adesina K, Larme A, Mills M, Ibraz T. A manual for the use of focus groups. Man in India 1993; 73(1): 17-27.

31. Ritchie J, Lewis J. Qualitative research practice: A guide for social science students and researchers. 1st ed. Thousand Oaks, CA: SAGE Publications; 2003.

32.Smith J, Firth J. Qualitative data analysis: the framework approach. Nurse researcher 2011; 18(2): 52-62.

33. Srivastava A, Thomson SB. Framework analysis: A qualitative methodology for applied policy research. Journal of Administration \& Governance 2009; 4(2): 72-79.

34.Emery D, Cowan A, Eaglestone B, Heyes B, Procter P, Willis T. Care plus. The University of Sheffield; 2002.

35. Read S, Ashman M, Scott C, Savage J. Evaluation of the modern matron role in a sample of NHS trusts. Sheffield and London - UK: The Royal College of Nursing Institute and The University of Sheffield School of Nursing and Midwifery; 2004.

36. Gerrish K, Chau R, Sobowale A, Birks E. Bridging the language barrier: The use of interpreters in primary care nursing. Health Soc Care Community 2004; 12(5): 407-413.

37. Gale NK, Heath G, Cameron E, Rashid S, Redwood S. Using the framework method for the analysis of qualitative data in multi-disciplinary health research. BMC Medical Research Methodology 2013; 13(1): 117.

38.Denzin NK, Lincoln YS. Collecting and interpreting qualitative materials. Thousand Oaks, CA: SAGE Publications; 2003.

39. Calys M, Gagnon K, Jernigan S. A validation study of the Missouri alliance for home care fall risk assessment tool. Home Health Care Management \& Practice 2013; 25(2): 39-44.

40. Bowles KH, Pham J, O’Connor M, Horowitz DA. Information deficits in home care: A barrier to evidencebased disease management. Home Health Care Management \& Practice 2010; 22(4): 278-285.

41.Koru AG, Alhuwail D, Topaz M, Norcio A, Mills ME. Investigating the challenges and opportunities in home care to facilitate effective information technology adoption. Journal of the American Medical Directors Association 2016; 17: 53-58.

42. Naylor MD, Aiken LH, Kurtzman ET, Olds DM, Hirschman KB. The importance of transitional care in achieving health reform. Health Affairs 2011; 30(4): 746-754.

43. Myrka A, Butterfield S, B GJ, Amin P, Ambrosy S, Woellmer C, Glock S. A systems-based medication reconciliation process: with implications for home healthcare. Home Healthcare Nurse 2011; 29(10): 624-635.

44.Agency for Healthcare Research and Quality. Chapter 3. Developing change: Designing the medication reconciliation process; 2012 [cited 2015-12-31]. Available from: http://www.ahrq.gov/professionals/ quality-patient-safety/ patient-safety-resources/resources/match/match3.html.

45. Olsen RM, Hellzén O, Skotnes LH, Enmarker I. Breakdown in informational continuity of care during hospitalization of older home-living patients: A case study. International Journal of Integrated Care 2014; 14.

46. Hellesø R, Lorensen M, Sorensen L. Challenging the information gap - the patients transfer from hospital to home health care. International Journal of Medical Informatics 2004; 73(7-8): 569-580.

47. Haggerty JL, Reid RJ, Freeman GK, Starfield BH, Adair CE, McKendry R. Continuity of care: A multidisciplinary review. British Medical Journal 2003; 327(7425): 1219-1221.

48. Campinha-Bacote J, Narayan MC. Culturally competent health care in the home. Home Care Provider 2002; 5(6): 213-219.

49. Hines D. Cultural competence: Assessment and education resources for home care and hospice clinicians. Home Healthcare Nurse 2012; 30(1): 38-45.

50. Koru G, Alhuwail D, Rosati RJ. Identifying the Key Performance Improvement Domains for Home Health Agencies. SAGE Open Medicine 2015; 3.

51.Knoerl AM. Cultural awareness and home care planning. Home Health Care Management \& Practice. 2004; 16(4): 269-270.

52.Patterson PK, Blehm R, Foster J, Fuglee K, Moore J. Nurse information needs for efficient care continuity across patient units. The Journal of Nursing Administration 1995; 25(10): 28-36. 
53. Burton LC, Anderson GF, Kues IW. Using electronic health records to help coordinate care. The Milbank Quarterly 2004; 82(3): 457-481.

54. Cipriano PF, Bowles K, Dailey M, Dykes P, Lamb G, Naylor M. The importance of health information technology in care coordination and transitional care. Nursing Outlook 2013; 61(6): 475-489.

55. Mack KA, Liller KD, Baldwin G, Sleet D. Preventing unintentional injuries in the home using the health impact pyramid. Health education \& behavior 2015; 42(10): 115S-122S.

56. Ferranti JM, Musser RC, Kawamoto K, Hammond WE. The Clinical Document Architecture and the Continuity of Care Record: a critical analysis. Journal of the American Medical Informatics Association 2006; 13(3): 245-252.

57. D’Amore JD, Sittig DF, Ness RB. How the Continuity of Care Document can advance medical research and public health. American Journal of Public Health 2012; 102(5): e1-e4.

58. Taylor SP, Ledford R, Palmer V, Abel E. We need to talk: an observational study of the impact of electronic medical record implementation on hospital communication. BMJ Quality \& Safety 2014; 23(7): 584-588. 